Article

\title{
Molecular and Cytogenetic Characterization of New Wheat- Dasypyrum breviaristatum Derivatives with Post-Harvest Re-Growth Habit
}

\author{
Hongjun Zhang ${ }^{1}$, Guangrong Li ${ }^{1}$, Donghai Li ${ }^{1}$, Dan Gao ${ }^{1}$, Jie Zhang ${ }^{1}$, Ennian Yang ${ }^{2}$ \\ and Zujun Yang 1,*
}

1 School of Life Science and Technology, University of Electronic Science and Technology of China, Chengdu 610054, China; E-Mails: hongjunzh01@sina.com (H.Z.); ligr28@uestc.edu.cn (G.L.); lidonghaixy@163.com (D.L.); gaodangaodan2010@163.com (D.G); christine219@163.com (J.Z.)

2 Crop Research Institute, Sichuan Academy of Agricultural Sciences, Chengdu 610066, China; E-Mail: yangennian@126.com

* Author to whom correspondence should be addressed; E-Mail: yangzujun@uestc.edu.cn; Tel.: +86-28-8320-6556; Fax: +86-28-8320-8238.

Academic Editor: Sean Mayes

Received: 25 August 2015 / Accepted: 18 November 2015 / Published: 26 November 2015

\begin{abstract}
A novel Dasypyrum species, Dasypyrum breviaristatum, serves as a valuable source of useful genes for wheat improvement. The development and characterization of new wheat- $D$. breviaristatum introgression lines is important to determine the novel gene(s) on specific chromosome(s). We first used multi-color fluorescence in situ hybridization (FISH) to identify the individual $D$. breviaristatum $\mathrm{V}^{\mathrm{b}}$ chromosomes in a common wheat $-D$. breviaristatum partial amphiploid, TDH-2. The FISH patterns of D. breviaristatum chromosomes were different from those of D. villosum chromosomes. Lines D2146 and D2150 were selected from a cross between wheat line MY11 and wheat $-D$. breviaristatum partial amphiploid TDH-2, and they were characterized by FISH and PCR-based molecular markers. We found that D2150 was a monosomic addition line for chromosome $5 \mathrm{~V}^{\mathrm{b}}$ of $D$. breviaristatum, while D2146 had the $5 \mathrm{~V}^{\mathrm{b}} \mathrm{L}$ chromosome arm translocated with wheat chromosome 5AS. Molecular marker analysis confirmed that the introduced D. breviaristatum chromosome $5 \mathrm{~V}^{\mathrm{b}} \mathrm{L}$ translocation possessed a duplicated region homoeologous to $5 \mathrm{AS}$, revealing that the $5 \mathrm{AS} .5 \mathrm{~V}^{\mathrm{b}} \mathrm{L}$ translocation may not functionally compensate well. The dwarfing and the pre-harvest re-growth habits observed in the wheat- $D$. breviaristatum chromosome $5 \mathrm{~V}^{\mathrm{b}}$ derivatives may be useful for future development of perennial growth wheat lines.
\end{abstract}


Keywords: Dasypyrum breviaristatum; fluorescence in situ hybridization; molecular markers; wheat

\section{Introduction}

The genus Dasypyrum (or Haynaldia) consists of two species, Dasypyrum villosum and D. breviaristatum. Cytological and molecular evidence suggest significant genomic diversification between the two species, and therefore the genome symbols of D. villosum and D. breviaristatum were assigned to $\mathrm{V}$ and $\mathrm{V}^{\mathrm{b}}$, respectively [1,2]. Recently, Baum et al. [3] suggested the genome constitution of tetraploid D. breviaristatum as $\mathrm{VVV}^{\mathrm{b}} \mathrm{V}^{\mathrm{b}}(2 n=4 x=28)$ based on the evolutionary analysis of the nr5S DNA multi-gene family. Both Dasypyrum species displayed several agronomical important traits including those of disease resistance, high protein quality and drought tolerance, which offer valuable resources for wheat improvement [4,5]. The D. villosum species has been extensively hybridized to wheat, and several disease resistance genes have been successfully transferred to wheat [6-8]. With the aim to transfer useful genes from $D$. breviaristatum into wheat, we produced a wheat $-D$. breviaristatum partial amphiploid and several wheat-D. breviaristatum introgression lines by chromosome manipulation [9-11].

Precise identification of the alien chromosomes and wheat-alien recombinant chromosomes is essential for investigation of evolution and utilization of novel chromatin in wheat breeding. Chromosome C-banding and fluorescence in situ hybridization (FISH) are powerful techniques to visualize alien chromatin in wheat-alien hybrids [12,13]. The large heterochromatic C-bands of D. villosum chromosomes enable the identification of the D. villosum chromosomes and their rearrangement in the wheat background [14,15]. Recently, Zhang et al. [16] established a FISH karyotype of $D$. villosum chromosomes by probes of $\mathrm{pSc} 119.2$, pAs1, 45S and 5SrDNA. Meanwhile, the simple sequence repeat $(\mathrm{GAA})_{n}$ can be used as a FISH probe to characterize the individual D. villosum chromosomes [17]. However, D. breviaristatum chromosomes displayed less telomeric heterochromatin and generally had different C-banding patterns compared to those of D. villosum [18] The detailed karyotype of $D$. breviaristatum chromosomes needs to be established by molecular and cytogenetic methods.

Development of "perennial wheat" has been proposed as a potential method for sustainability of agricultural production, food security, and environmental quality [19]. Many Triticeae species have been used as donors of perennial growth habit to improve wheat [20,21]. As a perennial Dasypyrum species, D. breviaristatum has a strong perennial character with a post-harvest regrowth (PHR) habit, which could be transferred to a wheat background. Here we aimed to establish the karyotype of D. breviaristatum chromosomes in a wheat background, and characterize the novel wheat $-D$. breviaristatum introgression lines by using multicolor-fluorescence in situ hybridization and molecular markers. 


\section{Materials and Methods}

\subsection{Plant Materials}

D. breviaristatum accession PI 546317 (genome $\mathrm{VVV}^{\mathrm{b}} \mathrm{V}^{\mathrm{b}}, 2 n=4 x=28$ ) was obtained from the National Small Grains Collection at Aberdeen, Idaho, USA. The wheat-D. breviaristatum partial amphiploid TDH-2 (genome AABBV $\mathrm{V}^{\mathrm{b}}, 2 n=6 x=42$ ) was as described by Yang et al. [9]. Triticum turgidum cv. Jorc-69- D. villosum amphiploid ABV (genome AABBVV, $2 n=6 x=42$ ) was developed and provided by Prof. Hua-Ren Jiang at Sichuan Agricultural University, China [22]. Line D2146 and D2150 was obtained from the $\mathrm{BC}_{1} \mathrm{~F}_{4}$ generation of a cross between wheat line MY11 and TDH-2.

\subsection{Fluorescence in Situ Hybridization (FISH)}

Seedling root tips were collected and pretreated in water at $0{ }^{\circ} \mathrm{C}$ for $24 \mathrm{~h}$ and fixed in ethanol-acetic acid (3:1) for conventional squashes. The nitrous oxide treated root-tip followed by enzyme digested drop method was also reported by Tang et al. [23]. FISH with the LTR probe pDbH12 was used to detect the Dasypyrum genome in a wheat background as reported by Yang et al. [24]. The synthesized probes Oligo-pSc119.2, Oligo-pTa535, Oligo-(GAA)6 were used in the FISH analysis [23]. The hybridization and detection protocols were as described by Fu et al. [25]. Microphotographs of FISH chromosomes were taken with an Olympus BX-51 microscope equipped with a DP-70 CCD camera.

\subsection{Molecular Marker Analysis}

DNA was extracted from young leaves of D. breviaristatum, TDH-2, ABV, lines D2146, D2150 and Triticum aestivum cv. "Chinese Spring" (CS). PCR-based Landmark Unique Gene (PLUG) primers and EST based primers were designed according to Ishikawa et al. [26] and Fang et al. [27], respectively. Polymerase chain reaction (PCR) was performed in an Icycler thermalcycler (Bio-RAD Laboratories, Emeryville, CA, USA) in a $25 \mu \mathrm{L}$ reaction, containing $10 \mathrm{mmol}$ Tris- $\mathrm{HCl}(\mathrm{pH} 8.3$ ), $2.5 \mathrm{mmol} \mathrm{MgCl}_{2}, 200 \mu \mathrm{mol}$ of each dNTP, $100 \mathrm{ng}$ template DNA, $0.2 \mathrm{U}$ Taq polymerase (Takara, Japan) and $400 \mathrm{nmol}$ of each primer. The cycling parameters were $94{ }^{\circ} \mathrm{C}$ for $3 \mathrm{~min}$ for denaturation; followed by 35 cycles at $94{ }^{\circ} \mathrm{C}$ for $1 \mathrm{~min}, 55^{\circ} \mathrm{C}$ for $1 \mathrm{~min}, 72{ }^{\circ} \mathrm{C}$ for $2 \mathrm{~min}$; and a final extension at $72{ }^{\circ} \mathrm{C}$ for $10 \mathrm{~min}$. The amplified products were separated by $8 \%$ PAGE gel as described by Hu et al. [28].

\subsection{Agronomic Performance Observations}

Field agronomic trait observations were performed at the Xindu Experimental Station, Chengdu, China during the 2012-2015 wheat-growing season. A post-harvest re-growth (PHR) habit displays a second phase of tiller initiation after the sexual cycle of the first phase is completed [29]. After harvesting, the $40 \mathrm{~cm}$ stubble of the lines was left in the field for evaluation of re-growth. Either a crown or tiller emerging from the soil surface was taken to be regrowth, with regrowth expressed as a percentage of PHR measured one month after harvest. 


\section{Results}

\subsection{FISH Karyotype of D. breviaristatum Chromosomes in TDH-2}

In order to establish the FISH karyotype of D. breviaristatum chromosomes, a partial amphiploid between wheat $-D$. breviaristatum [9], the mitotic metaphase chromosomes of TDH-2 that were hybridized using the Oligo-pSc119.2, Oligo-pTa535, Oligo-(GAA) 7 and pDb12H probes through sequential multicolor-FISH (Figure 1). As shown in Figure 1A, strong hybridization signals of the Dasypyrum specific probe pDb12H [23] were observed on all 14 chromosomes of TDH-2, indicating that they are D. breviaristatum chromosomes. Subsequently, Oligo-pSc119.2 and Oligo-pTa535 probes were also used to identify the $D$. breviaristatum chromosomes (temporarily designed from A to $\mathrm{G})$ of the same metaphase of the TDH-2 partial amphiploid (Figure 1B). We found that the signals using Oligo-pSc119.2 probe were mainly located on the terminal sites of one arm in four pairs of chromosomes (C, D, F and G), and both arms in two pairs of chromosomes (B and F) (Figure 1B and Figure 2A). The hybridization signals of Oligo-pTa535 were distributed on all the chromosome arms of D. breviaristatum, including signals at the terminal, sub-terminal or interstitial sites and occasionally at centromeric positions (Figure 1B and Figure 2A). The Oligo- (GAA) 7 probe hybridized to five pairs of $D$. breviaristatum chromosomes (A-B, D, F-G) at their centromeric regions or sub-terminal regions, while two pairs of chromosomes ( $\mathrm{C}$ and $\mathrm{E})$ were free of Oligo- $(\mathrm{GAA})_{7}$ hybridization sites (Figure 1C and Figure 2A). Based on the distribution of the above four probes, the FISH karyotype of the seven pairs of D. breviaristatum chromosomes in TDH-2 was obtained (Figure 2B). Compared with the reported FISH karyotype of wheat and other Triticeae genomes [16,17,24,25], we conclude that FISH can precisely identify the D. breviaristatum chromosomes in a wheat background.
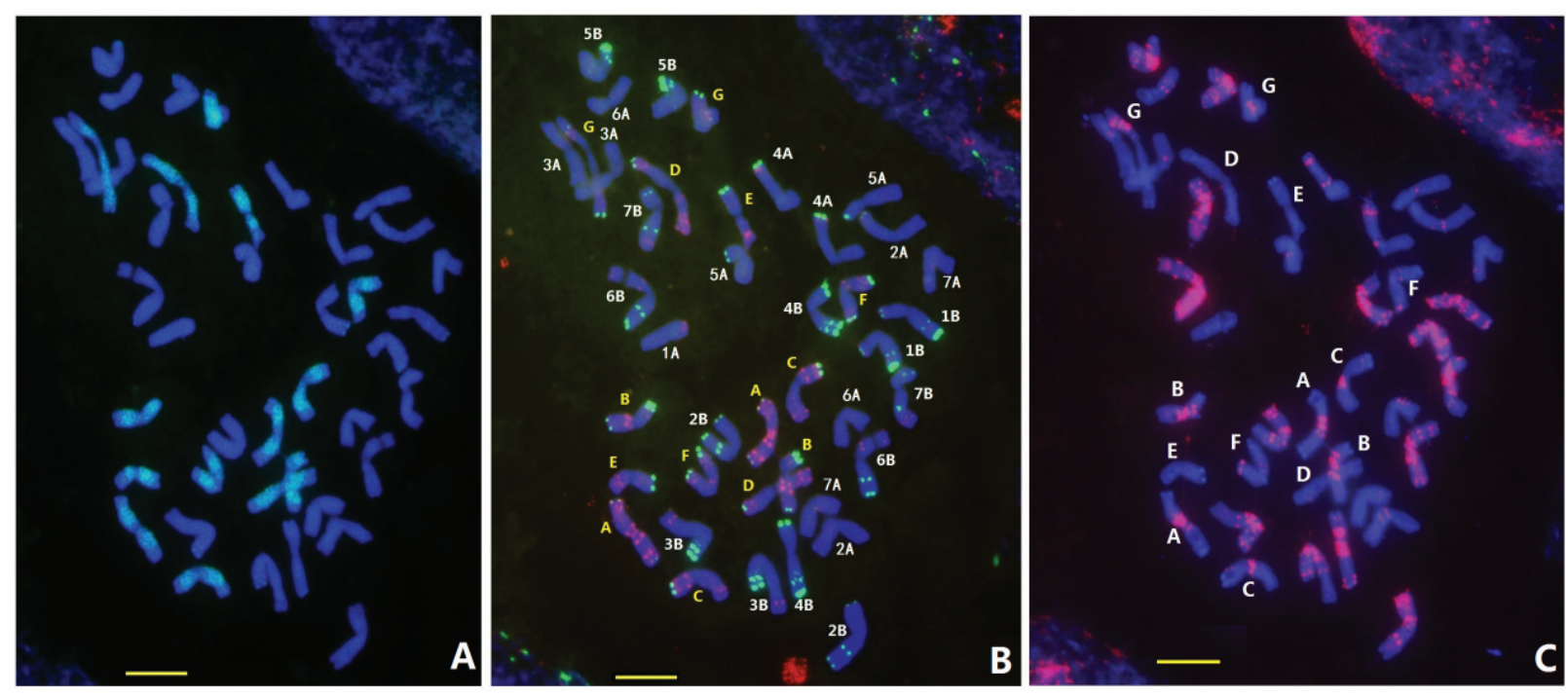

Figure 1. Sequential fluorescence in situ hybridization FISH of wheat - D. breviaristatum partial amphiploid (TDH-2) with probes pDb12H (A), Oligo-pSc119.2 (green) and Oligo-pTa535 (red) (B) and Oligo-(GAA)7 (C) (red). The bars indicated $10 \mu \mathrm{m}$. 


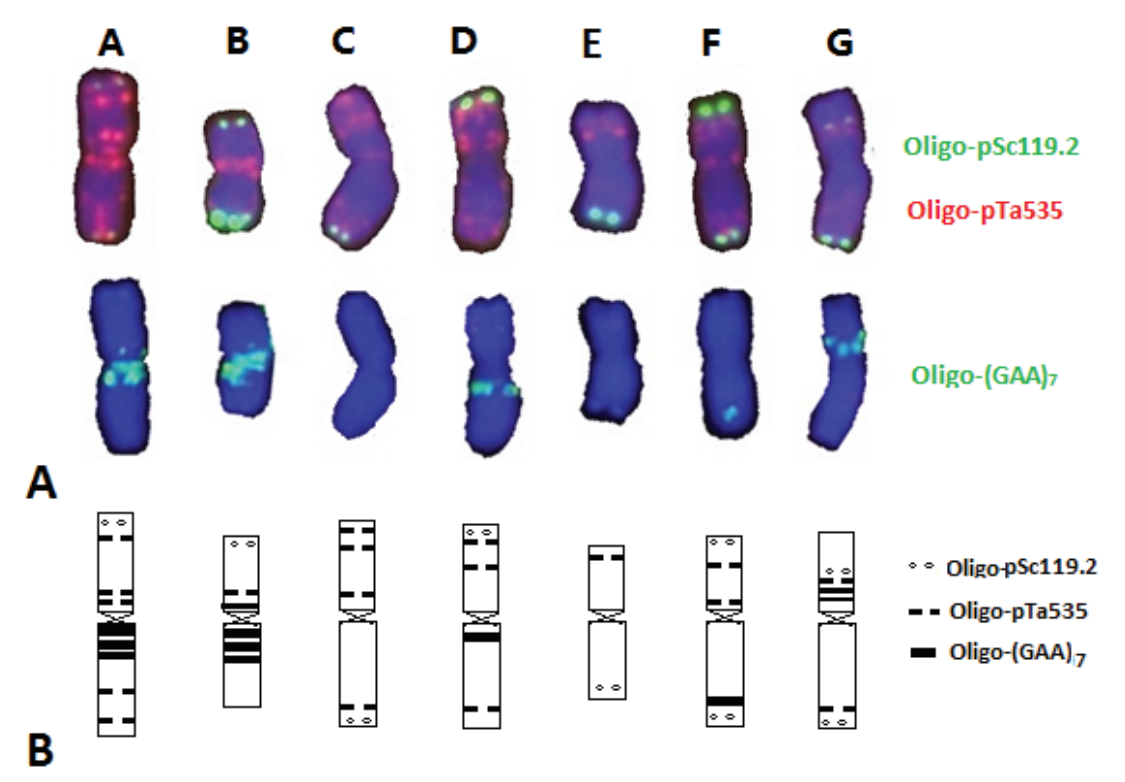

Figure 2. Karyotype (A) and ideogram (B) of D. breviaristatum chromosomes presents in the wheat $-D$. breviaristatum partial amphiploid (TDH-2).

\subsection{FISH of D2150 and D2146}

The probes Oligo-pSc119.2, Oligo-pTa535, Oligo-(GAA) 7 and pDb12H were used to identify the chromosomes in metaphase spreads of wheat - D. breviaristatum D2146 and D2150 lines (Figure 3A). FISH with the $\mathrm{pDb} 12 \mathrm{H}$ probe revealed that $\mathrm{D} 2150$ had 43 chromosomes including a D. breviaristatum chromosome (Figure 3A). The sequential FISH using Oligo-Sc119.2 and Oligo-pTa535 (Figure 3B), as well as the Oligo-(GAA)6 (Figure 3C), suggested that in the D2150 line, the added D. breviaristatum chromosome was identical to the chromosome G of TDH-2 (Figure 2). FISH by pDb12H indicated that D2146 carried a pair of wheat $-D$. breviaristatum translocated chromosomes (Figure 3D). The FISH with probes Oligo-pSc119.2 and Oligo-pTa535 (Figure 3E), and Oligo-(GAA)6 (Figure 3F), indicated that the translocated chromosome in D2146 line showed one weak Oligo-pSc119.2 band at the end of the short arm while the long arm of D. breviaristatum showed both a strong pSc119.2 and faint Oligo-pTa535 sites at the terminal regions. We deduced that the short arm showed the typical FISH pattern of 5AS and the long arm resembled that of chromosome $\mathrm{G}$ of D. breviaristatum.
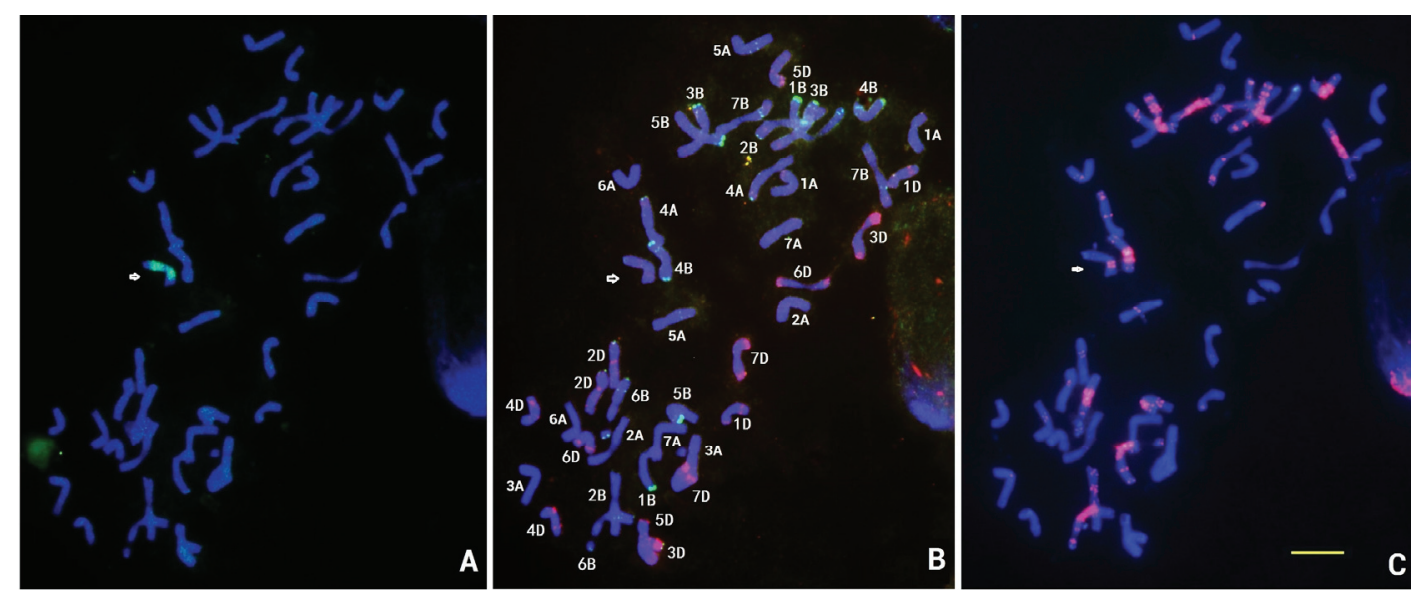

Figure 3. Cont. 

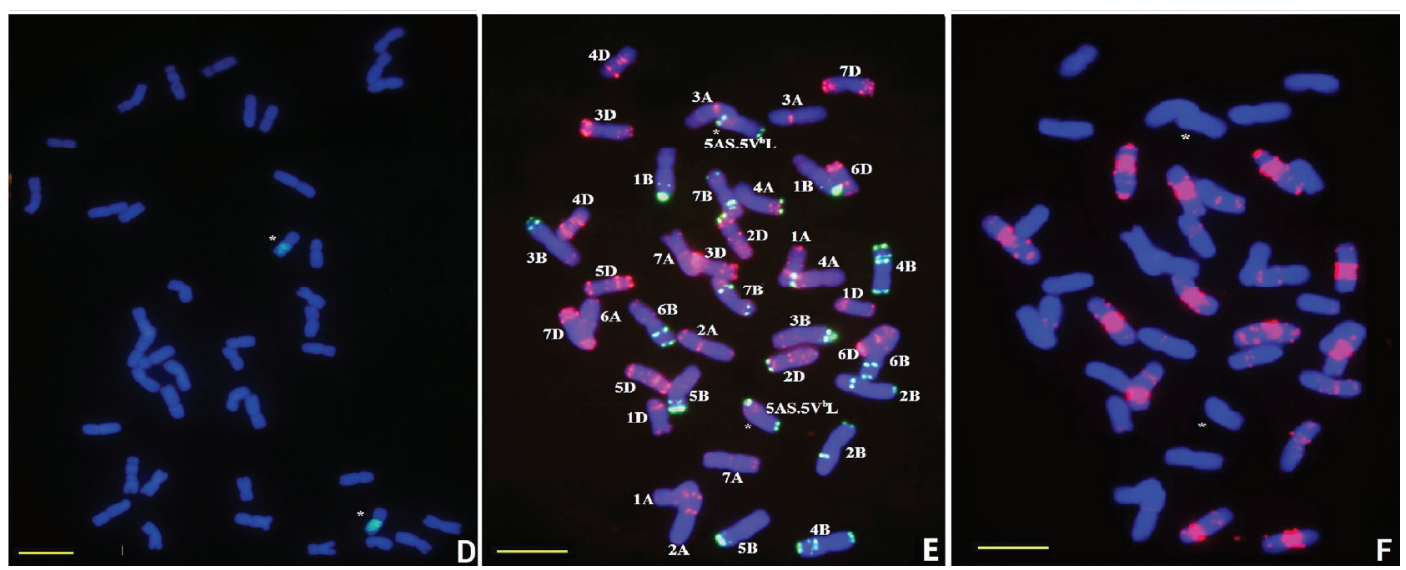

Figure 3. FISH of wheat $-D$. breviaristatum derivative lines. (A-C) wheat-monosomic addition line for chromosome $5 \mathrm{~V}^{\mathrm{b}}$ of $D$. breviaristatum (D2150) and (D-F) $5 \mathrm{AS} .5 \mathrm{~V}^{\mathrm{b}} \mathrm{L}$ translocation line (D2146). The probes pDb12H (A,D) and Oligo-pSc119.2 (B,E) are showed in green. The probes Oligo-pTa535 $(\mathbf{B}, \mathbf{E})$ and Oligo- $(\mathrm{GAA})_{7}(\mathbf{C}, \mathbf{F})$ are showed in red. Arrows and stars show the D. breviaristatum chromatin, and bars indicate $10 \mu \mathrm{m}$.

\subsection{Molecular Marker Analysis}

In order to determine the linkage group of the D. breviaristatum chromatin in D2146, molecular markers based on the syntenic regions between wheat EST and rice genomic DNA sequences were used to identifying alien fragments corresponding to the wheat linkage group(s) [30-32]. A total of 12 PLUG markers from wheat homologous group 5 [26] and 22 Hordeum californicum chromosome $5 \mathrm{H}^{\mathrm{c}}$ specific markers [27] were used. The markers were tested on D2146 and its parents (MY11 and TDH-2) as well as D. breviaristatum. We found that 13 markers generated specific bands from D. breviaristatum and TDH-2. Three markers were assigned to the short arm and 10 markers were located on long arm of $D$. breviaristatum chromosome $5 \mathrm{~V}^{\mathrm{b}}$ (Table 1). As shown in Figure 4, the PLUG markers TNAC1554 and TNAC1567 amplified fragments from the long arm of chromosomes 5A, 5B, and 5D of common wheat CS. The chromosome 5AL specific fragments were absent in D2146, while the D. breviaristatum specific bands appeared in D2146. These results suggested that the 5AS chromosome arm was translocated to the $5 \mathrm{~V}^{\mathrm{b}} \mathrm{L}$. However, marker TNAC1485 simultaneously amplified 5AS and $5 \mathrm{~V}^{\mathrm{b}} \mathrm{L}$ specific bands in the D2146 translocation line (Figure 4A). As shown in Figure 5, we conclude that D2146 translocation line may contain a putative duplicated fragment of homologous group 5 from wheat and Dasypyrum chromosomes $5 \mathrm{~V}^{\mathrm{b}}$.

Table 1. The PCR primers used in this study.

\begin{tabular}{cllcc}
\hline Markers & $\begin{array}{c}\text { Homoeologous } \\
\text { Relationship }\end{array}$ & Primer Sequences & Enzymes & $\begin{array}{c}\text { Dasypyrum } \\
\text { Specific Bands }\end{array}$ \\
\hline TNAC 1485 a & 5AS,5BS, 5DS & $\begin{array}{l}\text { F: CCCAAGTTCACTAACTTCGTTG } \\
\text { R: AAATAGTCCTGCATATCTCCTGT }\end{array}$ & Taq I & $5 \mathrm{~V}^{\mathrm{b} L}$ \\
TNAC 1497 a & 5AS,5BS, 5DS & $\begin{array}{l}\text { F: ATCAAACCTGACGGTGTTCAG } \\
\text { R: CATGCAGACTACAGGTCCAGA }\end{array}$ & Taq I & $5 \mathrm{~V}^{\mathrm{b} S}$ \\
TNAC1503 a & 5AS,5BS, 5DS & $\begin{array}{l}\text { F: TGAGGTTGGTTCTCATCTGGA } \\
\text { R: CGTTGGAAACAATCTGAATGG }\end{array}$ & Taq I & $5 \mathrm{~V}^{\mathrm{b} S}$ \\
\hline
\end{tabular}


Table 1. Cont.

\begin{tabular}{|c|c|c|c|c|}
\hline Markers & $\begin{array}{c}\text { Homoeologous } \\
\text { Relationship }\end{array}$ & Primer Sequences & Enzymes & $\begin{array}{c}\text { Dasypyrum } \\
\text { Specific Bands }\end{array}$ \\
\hline TNAC1588 ${ }^{a}$ & 5AS,5BS, 5DS & $\begin{array}{l}\text { F: AAATCAGCAGGTGGCCAGTAT } \\
\text { R: AAATGGCGCACCATACTCAAG }\end{array}$ & Taq I & $5 \mathrm{~V}^{\mathrm{b}} \mathrm{S}$ \\
\hline TNAC1540 a & $5 \mathrm{AL}, 5 \mathrm{BL}, 5 \mathrm{DL}$ & $\begin{array}{l}\text { F: AACCTCAAGCACTGTCAGCAT } \\
\text { R: TTGCAGATCCTCTCAATCTCG }\end{array}$ & Hea III & $5 \mathrm{~V}^{\mathrm{b}} \mathrm{L}$ \\
\hline TNAC $1554^{\mathrm{a}}$ & $5 \mathrm{AL}, 5 \mathrm{BL}, 5 \mathrm{DL}$ & $\begin{array}{l}\text { F: TTGCTAGCTCAGCACAGTTTG } \\
\text { R: TTCTTGGTCACTCTGAGCGTA }\end{array}$ & Taq I & $5 \mathrm{~V}^{\mathrm{b}} \mathrm{L}$ \\
\hline TNAC1559 a & $5 \mathrm{AL}, 5 \mathrm{BL}, 5 \mathrm{DL}$ & $\begin{array}{l}\text { F: AAACAAGGCCCTGAAACACTT } \\
\text { R: CATTGTCAGGCTATGGGACAT }\end{array}$ & Hea III & $5 \mathrm{~V}^{\mathrm{b}} \mathrm{L}$ \\
\hline TNAC $1567^{\text {a }}$ & 5AL,5BL, 5DL & $\begin{array}{l}\text { F: ATGTTGGCTTTATACCAATGC } \\
\text { R: AGGTGCGGCTTCACTATCTTT }\end{array}$ & $T a q \mathrm{I}$ & $5 \mathrm{~V}^{\mathrm{b}} \mathrm{L}$ \\
\hline TNAC $1618^{a}$ & $5 \mathrm{AL}, 5 \mathrm{BL}, 5 \mathrm{DL}$ & $\begin{array}{l}\text { F: GTTGGCTGTTGATGGTAAGGA } \\
\text { R: GGAGGCCACCAACTAATGTTT }\end{array}$ & Taq I & $5 \mathrm{~V}^{\mathrm{b}} \mathrm{L}$ \\
\hline $\mathrm{BE} 445873^{\mathrm{b}}$ & 5AL,5BL,5DL & $\begin{array}{l}\text { F: ATCTCGACAAAGATCAAGCA } \\
\text { R: CGAGAAGTTCCATCTCATTG }\end{array}$ & - & $5 \mathrm{~V}^{\mathrm{b}} \mathrm{L}$ \\
\hline $\mathrm{BE} 445380^{\mathrm{b}}$ & $5 \mathrm{AL}, 5 \mathrm{BL}$ & $\begin{array}{l}\text { F: GCTACCACAGTTGCTACAGG } \\
\text { R: ATCGACGTAACACGAATCAC }\end{array}$ & - & $5 \mathrm{~V}^{\mathrm{b}} \mathrm{L}$ \\
\hline $\mathrm{BE} 604833^{\mathrm{b}}$ & $5 \mathrm{AL}$ & $\begin{array}{l}\text { F: GCAGATTCACCCACTCTGTA } \\
\text { R: ATACGCGGTCACATCATAAA }\end{array}$ & - & $5 \mathrm{~V}^{\mathrm{b}} \mathrm{L}$ \\
\hline $\mathrm{BE} 443610^{\mathrm{b}}$ & 5AL,5BL,5DL & $\begin{array}{l}\text { F: ACCAATGAAGGACCATCTCT } \\
\text { R; CATTTCTCAGCTTGTCCAAC }\end{array}$ & - & $5 \mathrm{~V}^{\mathrm{b}} \mathrm{L}$ \\
\hline
\end{tabular}

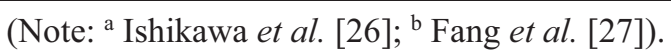

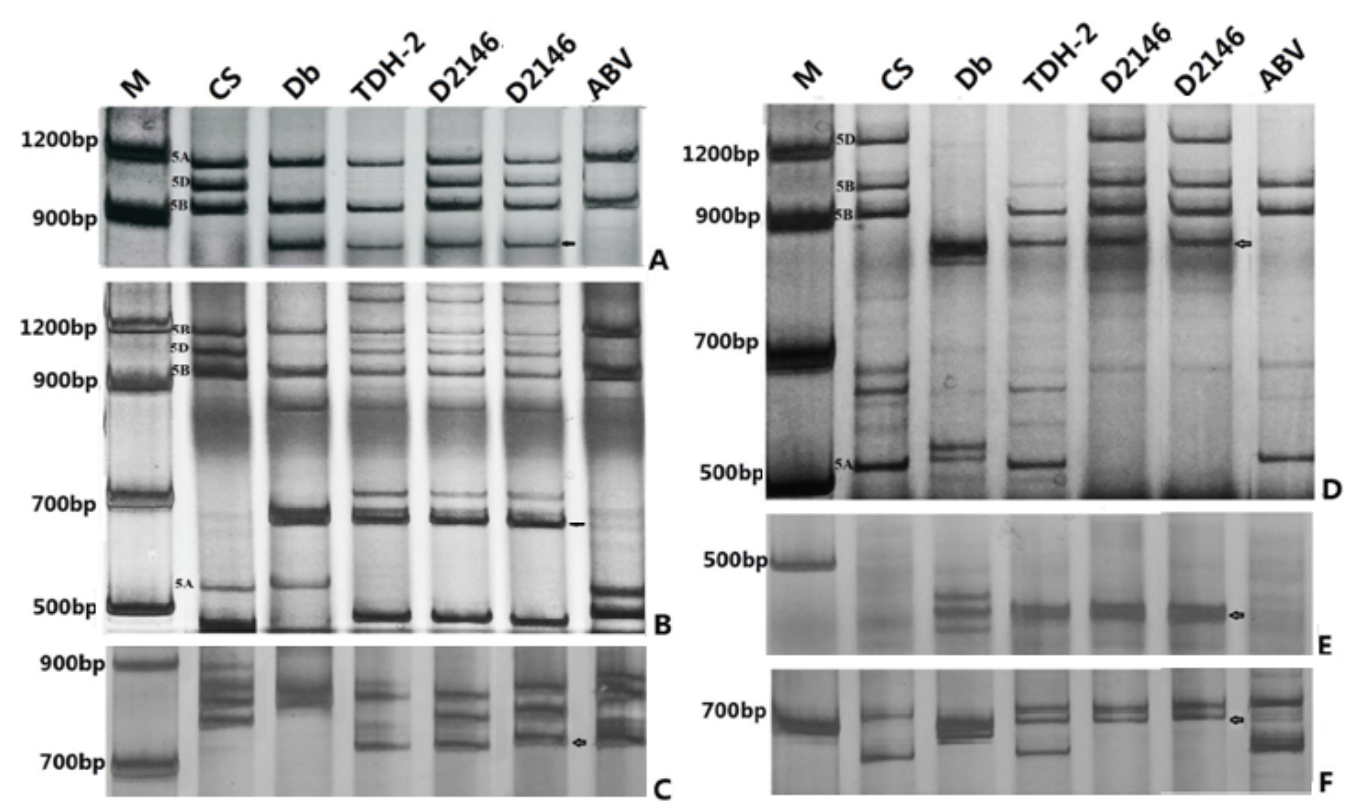

Figure 4. PCR amplification of molecular markers in wheat $-D$. breviaristatum lines. (A) TNAC1485; (B) TNAC1554; (C) BE443610; (D) TNA1567; (E) BE445380 and (F) BE604833. CS: "Chinese Spring" wheat; Db: D. breviaristatum; TDH-2: wheat—D. breviaristatum partial amphiploid; D2146: 5AS.5V $\mathrm{V}$ translocation line; ABV: Triticum turgidum, D. villosum amphiploid. The arrows indicate the $D$. breviaristatum specific bands. 


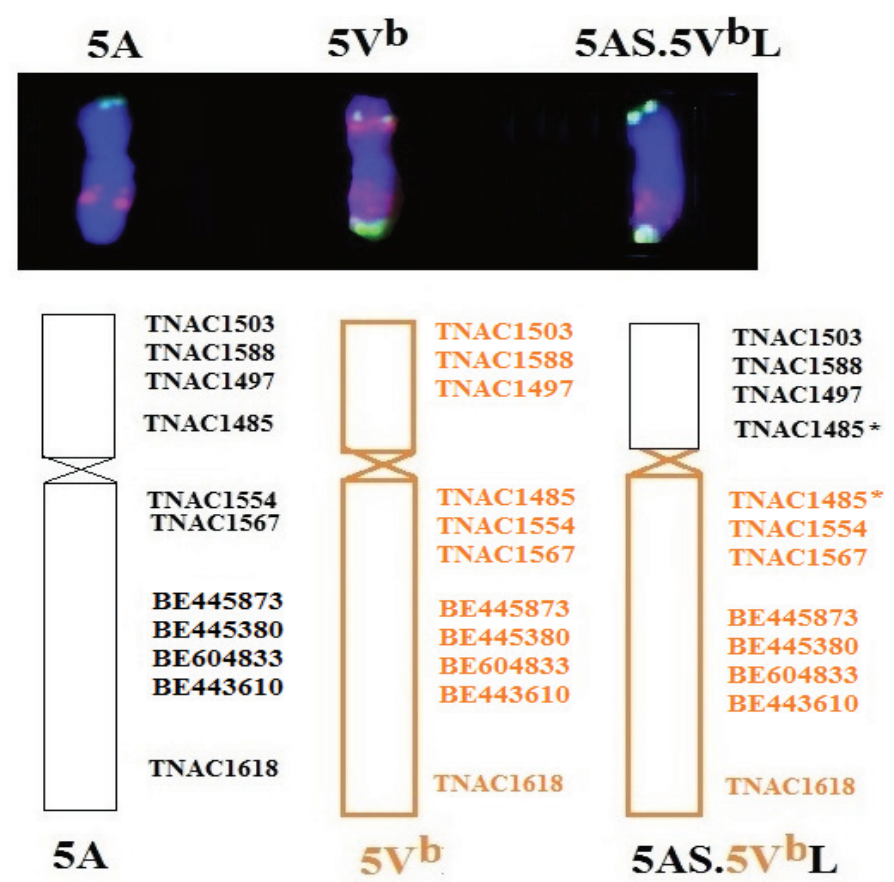

Figure 5. FISH karyotypes and molecular markers distributed on chromosomes $5 \mathrm{~A}, 5 \mathrm{~V}^{\mathrm{b}}$, and $5 \mathrm{AS} .5 \mathrm{~V}^{\mathrm{b}} \mathrm{L}$ translocation. The stars indicates the duplicated markers on chromosome $5 \mathrm{AS} .5 \mathrm{~V}^{\mathrm{b}} \mathrm{L}$.

\subsection{Agronomic Traits Observation}

A set of agronomic traits were measured on 15 plants of the D. breviaristatum $5 \mathrm{~V}^{\mathrm{b}}$ monosomic addition line, $5 \mathrm{AS} .5 \mathrm{~V}^{\mathrm{b}} \mathrm{L}$ translocation line, wheat MY11 and the wheat $-D$. breviaristatum partial amphiploid (Table 2). Relative to the MY11 recurrent parent, all $5 \mathrm{~V}^{\mathrm{b}}$ lines had reduced plant height, suggesting that chromosome $5 \mathrm{~V}^{\mathrm{b}}$ carries a dwarfing gene(s) expressed in the wheat background. No significant differences were found for the length of spikes in the $5 \mathrm{~V}^{\mathrm{b}}$ monosomic addition line, 5AS. $5 \mathrm{~V}^{\mathrm{b}} \mathrm{L}$ translocation line and the wheat control. The $5 \mathrm{AS} .5 \mathrm{~V}^{\mathrm{b}} \mathrm{L}$ translocation line had a decreased number of spikelets per spike and a 1000-kernel weight compared to its wheat parent indicating that the translocation may have an unfavorable effect on grain yield relative to wheat lines.

The wheat $-D$. breviaristatum partial amphiploid (TDH-2), D. breviaristatum $5 \mathrm{~V}^{\mathrm{b}}$ monosomic addition (D2150), and 5AS. 5 $\mathrm{V}^{\mathrm{b}} \mathrm{L}$ translocation line (D2146) were found to have PHR habits under field conditions, while the parent MY11 has no PHR habit (Table 2). This result indicates that D. breviaristatum $5 \mathrm{~V}^{\mathrm{b}} \mathrm{L}$ may contain a gene(s) responsible for the PHR habit in annual wheat background.

Table 2. Agronomical traits of wheat $-D$. breviaristatum $5 \mathrm{~V}^{\mathrm{b}}$ derivatives.

\begin{tabular}{ccccccc}
\hline Genotype & $\begin{array}{c}\text { Plant Height } \\
(\mathbf{c m})\end{array}$ & $\begin{array}{c}\text { Length of } \\
\text { Spike }(\mathbf{c m})\end{array}$ & $\begin{array}{c}\text { No. of } \\
\text { Spikelet }\end{array}$ & $\begin{array}{c}\text { No. of } \\
\text { Spikes }\end{array}$ & $\begin{array}{c}\text { 1000-Kernel } \\
\text { Weight }(\mathbf{g})\end{array}$ & $\begin{array}{c}\text { Re-Growth } \\
\text { Score }\end{array}$ \\
\hline MY11 & $86.5 \pm 1.2 \mathrm{a}$ & $10.5 \pm 0.5 \mathrm{~b}$ & $20.6 \pm 0.2 \mathrm{a}$ & $4.2 \pm 0.2 \mathrm{~b}$ & $40.4 \pm 1.0 \mathrm{a}$ & 0 \\
TDH-2 & $70.0 \pm 4.8 \mathrm{~b}$ & $14.2 \pm 0.5 \mathrm{a}$ & $16.8 \pm 0.3 \mathrm{~b}$ & $7.5 \pm 0.5 \mathrm{a}$ & $16.5 \pm 0.6 \mathrm{c}$ & 86 \\
D2146 & $65.0 \pm 3.0 \mathrm{~b}$ & $10.0 \pm 0.4 \mathrm{~b}$ & $15.0 \pm 1.5 \mathrm{~b}$ & $3.0 \pm 0.5 \mathrm{~b}$ & $31.7 \pm 1.7 \mathrm{~b}$ & 56 \\
D2150 & $77.3 \pm 3.5 \mathrm{ab}$ & $11.0 \pm 0.5 \mathrm{~b}$ & $19.1 \pm 1.5 \mathrm{a}$ & $3.9 \pm 0.5 \mathrm{~b}$ & $39.7 \pm 0.8 \mathrm{a}$ & 78 \\
\hline
\end{tabular}

(Note: Values with the same letter in the same column do not differ significantly at $p<0.05$ ). 


\section{Discussion}

Fluorescence in situ hybridization (FISH) and genomic in situ hybridization (GISH) have been most useful techniques for investigating wheat - alien derivatives $[13,33]$. However, the conventional FISH protocols based on probe labeling, hybridization and detection were somewhat time-consuming and expensive [34,35]. The simpler and more efficient technique based on synthetic labeled oligonucleotides combined with non-denaturing FISH (ND-FISH) analysis were recently developed [24,36,37-38]. The synthetic oligonucleotides have been successfully used in FISH experiments, including the SSRs oligonucleotides and conserved nucleotides representing repetitive sequences, for karyotyping wheat, barley and rye chromosomes [39-41]. Recently, chromosome-specific painting in plant species using synthetic bulked oligonucleotides was also established [42]. In the present study, we detected the wheat and Dasypyrum chromatin using synthetic labeled oligonucleotides by ND-FISH with chromosome preparation of both a conventional squash method (Figures 1 and $3 \mathrm{~A}-\mathrm{C}$ ) and a nitrous oxide treated drop method (Figure 3D-F). In combination with Dasypyrum specific LTR probe pDb12H [23], we used the synthetic oligonucleotide probes, Oligo-pTa535, Oligo-pSc119.2, and Oligo-(GAA)7 [23], to develop a high resolution FISH karyotype of $D$. breviaristatum chromosomes in TDH-2. The FISH karyotypes can be used to the precisely locate the Dasypyrum chromatin in a wheat background. Comparing the FISH patterns of $D$. breviaristatum chromosomes present in the wheat $-D$. breviaristatum partial amphiploid (TDH-2) we found that the added D. breviaristatum chromosome in the D2150 line was identical to chromosome G of TDH-2 and that the fragment of D. breviaristatum present in the D2146 translocation line resembled the long arm of the chromosome G. Grosso et al. [17] used the simple sequence repeat $(\mathrm{GAA})_{n}$ as a FISH probe, to characterize the individual D. villosum chromosomes except for chromosome 1V. Recently, Zhang et al. [16] investigated the FISH distribution patterns of three repeated DNA sequences, pSc119.2, pAs1, 45S rDNA and 5S rDNA in the individual D. villosum chromosomes of D. villosum wheat addition and translocation lines. Compared with the FISH pattern of D. villosum chromosomes by Zhang et al. [16], we found that the seven pairs of $D$. breviaristatum chromosomes in the wheat $-D$. breviaristatum partial amphiploid displayed unique FISH patterns. Two pairs of $D$. breviaristatum chromosomes were lacking of (GAA) $n$ signals (Figure 2), the other five $D$. breviaristatum chromosomes pairs showed weaker (GAA)n signals than those of D. villosum chromosomes [17]. Moreover, the terminal regions of the short arms of three D. breviaristatum chromosomes showed strong pSc119.2 signals, while almost all D. villosum chromosome short arms have the pSc119.2 signals [16]. The results suggested that the accumulation of the repetitive sequences in D. breviaristatum chromosomes was less than in D. villosum chromosomes. The results were consistent with the evolutionary studies on the D. breviaristatum and D. villosum chromosomes by cytogenetic and molecular evidence $[43,44]$, and supported the idea that D. breviaristatum was ancestral to the D. villosum species $[3,5]$.

The production of compensating Robertsonian translocations is an important step for the evaluation of the breeding value of alien genetic materials [8]. Liu et al. [34] reported a set of wheat-D. villosum compensating Robertsonian translocations including a line TA5638 with T5DL·5V\#3S translocation between 5V and 5D. Zhang et al. [45] irradiated whole-arm wheat $-D$. villosum T5VS·5DL translocation line, and produced six homozygous small segment translocation lines with different fragment sizes of $5 \mathrm{VS}$, and a $5 \mathrm{VS}-6 \mathrm{AS} \cdot 6 \mathrm{AL}$ terminal translocation. In the present study, we produced a line (D2150) 
with a $D$. breviaristatum $5 \mathrm{~V}^{\mathrm{b}}$ chromosome in monosomy and a homozygous $\mathrm{T} 5 \mathrm{AS} \cdot 5 \mathrm{~V}^{\mathrm{b}} \mathrm{L}$ translocation line (D2146). Based on the molecular markers analysis, nine of 10 markers validated the introgression of $5 \mathrm{~V}^{b} \mathrm{~L}$. However, the specific amplification of marker TNAC1485 appeared in both chromosome $5 \mathrm{AS}$ and $5 \mathrm{~V}^{\mathrm{b}} \mathrm{L}$ arms (Figure $4 \mathrm{~A}$ ). It is suggested that the homologous duplication of the segments has occurred in this region in the T5AS $5 \mathrm{~V}^{\mathrm{b}} \mathrm{L}$ translocation lines. Recently, Li et al. [32] reported that the rye (Secale cereale L.) chromosome 5RL also contained homologous 5S wheat segments. These authors found that TNAC1485 marker was also located on rye chromosome 5RL. It is likely that the rearrangement occurred between the ancestral group 5 in Secale and in Dasypyrum chromosomes. Further evidence is needed to clarify the detail changes, possibly by inversion or centromeric movement during evolution by comparative genomic studies between wheat and related species.

Based on the agronomic traits evaluated (Table 2) it is likely that incomplete compensation of chromosome $5 \mathrm{AS} .5 \mathrm{~V}^{\mathrm{b}} \mathrm{L}$ in the D2146 line may cause inferior agronomic traits, such as reduced grain weight and spikelet number, compared with the wheat parent. Amphiploids and addition lines among wheat and some perennial species have shown the post-harvest re-growth habit (PHR) which has been investigated to produce potentially perennial wheat [46]. So far, wheat-Thinopyrum partial amphiploids [20,21] and wheat-Th. elongatum chromosome 4E addition lines [29] have been reported to express the PHR traits from these alien species in a wheat background [47]. As a perennial species, D. breviaristatum showed a strong perennial growth habit. The wheat $-D$. breviaristatum partial amphiploid (TDH-2) and the 5V $\mathrm{V}^{\mathrm{b}}$ derived lines (D2146 and D2150) also showed the PHR trait which putatively originated from $D$. breviaristatum parent. These results suggest that the PHR trait could be controlled by genes located on $D$. breviaristatum $5 \mathrm{~V}^{\mathrm{b}} \mathrm{L}$ chromosome arm. The lines with PHR habits will be useful for the development of perennial grain crops for feeding the animals.

\section{Conclusions}

Dasypyrum breviaristatum was a perennial species with a post-harvest re-growth character. Based on the molecular and cytogenetic studies, novel wheat $-D$. breviaristatum $5 \mathrm{~V}^{\mathrm{b}}$ chromosome addition and $5 \mathrm{AS} .5 \mathrm{~V}^{\mathrm{b}} \mathrm{L}$ translocation line were characterized. New D. breviaristatum $5 \mathrm{~V}^{\mathrm{b}}$ specific molecular markers were also produced. The wheat $-D$. breviaristatum derivatives and molecular markers may be favorable for future use of $D$. breviaristatum resources for development of perennial growth wheat lines.

\section{Acknowledgments}

We thank the National Natural Science Foundation of China (No. 31171542, 31101143, 31201203) for the financial support.

\section{Author Contributions}

Zujun Yang and Guangrong Li conceived of and designed the experiments. Hongjun Zhang, Dan Gao, Donghai Li and Jie Zhang performed the experiments. Zujun Yang, Ennian Yang and Guangrong Li analyzed the data. Zujun Yang wrote the paper. 


\section{Conflicts of Interest}

The authors declare no conflict of interest.

\section{References}

1. Gradzielewska, A. The genus Dasypyrum-part 1. The taxonomy and relationships within Dasypyrum and with Triticeae species. Euphytica 2006, 152, 429-440.

2. Liu, C.; Li, G.R.; Sunish, S.; Jia, J.Q.; Yang, Z.J.; Friebe, B.; Gill, B.S. Genome relationships in the genus Dasypyrum: Evidence from molecular phylogenetic analysis and in situ hybridization. Plant Syst. Evol. 2010, 288, 149-156.

3. Baum, B.R.; Edwards, T.; Johnson, D.A. What does the nr5S DNA multigene family tell us about the genomic relationship between Dasypyrum breviaristatum and D. villosum (Triticeae: Poaceae)? Mol. Genet. Genom. 2014, 289, 553-565.

4. Gradzielewska, A. The genus Dasypyrum-part 2. Dasypyrum villosum-a wild species used in wheat improvement. Euphytica 2006, 152, 441-454.

5. De Pace, C.; Vaccino, P.; Cionini, P.G.; Pasquini, M.; Bizzarri, M.; Qualset, C.O. Dasypyrum. In Wild Crop Relatives, Genomic and Breeding Resources, Cereals; Kole, C., Ed.; Springer-Verlag: Heidelberg, Germany, 2011; pp. 185-292.

6. Chen, P.D.; Qi, L.L.; Zhang, S.Z.; Liu, D.J. Development and molecular cytogenetic analysis of wheat-Haynaldia 6VS/6AL translocation lines specifying resistance to powdery mildew. Theor. Appl. Genet. 1995, 91, 1125-1128.

7. Yildirim, A.; Jones, S.S.; Murray, T.D. Mapping a gene conferring resistance to Pseudocercosporella herpotrichoides on chromosome $4 \mathrm{~V}$ of Dasypyrum villosum in a wheat background. Genome 1998, 41, 1-6.

8. Qi, L.L.; Pumphrey, M.O.; Friebe, B.; Zhang, P.; Qian, C.; Bowden, R.L.; Rouse, M.N.; Jin, Y.; Gill, B.S. A novel Robertsonian translocation event leads to transfer of a stem rust resistance gene (Sr52) effective against race Ug99 from Dasypyrum villosum into bread wheat. Theor. Appl. Genet. 2011, 123, 159-167.

9. Yang, Z.J.; Li, G.R.; Feng, J.; Jiang, H.R.; Ren, Z.L. Molecular cytogenetic characterization and disease resistance observation of wheat-Dasypyrum breviaristatum partial amphiploid and its derivatives. Hereditas 2005, 142, 80-85.

10. Liu, C.; Li, G.; Yan, H.; Zhou, J.; Hu, L.; Lei, M.; Ran, L.; Yang, Z. Molecular and cytogenetic identification of new wheat-D. breviaristatum additions conferring resistance to stem rust and powdery mildew. Breed. Sci. 2011, 61, 366-372.

11. Li, G.R.; Zhao, J.M.; Li, D.H.; Yang, E.N.; Huang, Y.F.; Liu, C.; Yang, Z.J. A novel wheat-Dasypyrum breviaristatum substitution line with stripe rust resistance. Cytogenet. Genome Res. 2014, 143, 280-287.

12. Friebe, B.; Jiang, J.; Raupp, W.J.; McIntosh, R.A.; Gill, B.S. Characterization of wheat-alien translocations conferring resistance to diseases and pests: Current status. Euphytica 1996, 91, 59-87.

13. Jiang, J.; Friebe, B.; Gill, B.S. Recent advances in alien gene transfer in wheat. Euphytica 1994, 73, 199-212. 
14. Friebe, B.; Cermeno, M.C.; Zeller, F.J. C-banding polymorphism and the analysis of nucleolar activity in Dasypyrum villosum (L.) Candargy, its added chromosomes to hexaploid wheat and the amphiploid Triticum dicoccum-D. villosum. Theor. Appl. Genet. 1987, 73, 337-342.

15. Linde-Laursen, I.B.; Frederiksen, S. Comparison of the Giemsa C-banded karyotypes of Dasypyrum villosum $(2 \times)$ and D. breviaristatum (4×) from Greece. Hereditas 1991, 114, 237-244.

16. Zhang, W.; Zhang, R.; Feng, Y.; Bie, T.; Chen, P. Distribution of highly repeated DNA sequences in Haynaldia villosa and its application in the identification of alien chromatin. Chin. Sci. Bull. 2013, 58, 890-897.

17. Grosso, V.; Farina, A.; Gennaro, A.; Giorgi, D.; Lucretti, S. Flow sorting and molecular cytogenetic identification of individual chromosomes of Dasypyrum villosum L. (H. villosa) by a single DNA probe. PLoS ONE 2012, 7, e50151.

18. Galasso, I.; Blanco, A.; Katsiotis, A.; Pignone, D.; Heslop-Harrison, H.S. Genomic organization and phylogenetic relationships in the genus Dasypyrum analysed by Southern and in situ hybridization of total genomic and cloned DNA probes. Chromosoma 1997, 106, 53-61.

19. Glover, J.D.; Reganold, J.P.; Bell, L.W.; Borevitz, J.; Brummer, E.C.; Buckler, E.S.; Cox, C.M.; Cox, T.S.; Crews, T.E.; Culman, S.W.; et al. Increased food and ecosystem security via perennial grains. Science 2010, 328, 1638-1639.

20. Cai, X.; Jones, S.S.; Murray, T.D. Molecular cytogenetic characterization of Thinopyrum genomes conferring perennial growth habit in wheat-Thinopyrum amphiploids. Plant Breed. 2001, 120, 21-26.

21. Larkin, P.J.; Newell, M.T.; Hayes, R.C.; Aktar, J.; Norton, M.R.; Moroni, S.J.; Wade, L.J. Progress in developing perennial wheats for grain and grazing. Crop Pasture Sci. 2014, 65, 1147-1164.

22. Jiang, H.R.; Dai, D.Q.; Sun, D.F.; Xiao, S.H. New artificial genetic resources of wheat: Several polyploids of Triticum-Dasypyrum. Sci. Agric. Sin. 1992, 25, 89.

23. Tang, Z.X.; Yang, Z.J.; Fu, S.L. Oligonucleotides replacing the roles of repetitive sequences pAs1, pSc119.2, pTa-535, pTa71, CCS1, and pAWRC.1 for FISH analysis. J. Appl. Genet. 2014, $55,313-318$.

24. Yang, Z.J.; Liu, C.; Feng, J.; Li, G.R.; Deng, K.J.; Zhou, J.P.; Ren, Z.L. Studies on genome relationship and species-specific PCR marker for Dasypyrum breviaristatum in Triticeae. Hereditas 2006, 143, 47-54.

25. Fu, S.; Yang, M.; Fei, Y.; Tan, F.; Ren, Z.; Yan, B.; Zhang, H.; Tang, Z. Alterations and abnormal mitosis of wheat chromosomes induced by wheat-rye monosomic addition lines. PLoS ONE 2013, 8, e 70483.

26. Ishikawa, G.; Nakamura, T.; Ashida, T.; Saito, M.; Nasuda, S.; Endo, T.; Wu, J.; Matsumoto, T. Localization of anchor loci representing five hundred annotated rice genes to wheat chromosomes using PLUG markers. Theor. Appl. Genet. 2009, 118, 499-514.

27. Fang, Y.; Yuan, J.; Wang, Z.; Wang, H.; Xiao, J.; Yang, Z.; Zhang, R.; Qi, Z.; Xu, W.; Hu, L.; et al. Development of $T$. aestivum L.-H. californicum alien chromosome lines and assignment of homoeologous groups of Hordeum californicum chromosomes. J. Genet. Genomics 2014, 41, $439-447$.

28. Hu, L.J.; Li, G.R.; Zeng, Z.X.; Chang, Z.J.; Liu, C.; Zhou, J.P.; Yang, Z.J. Molecular cytogenetic identification of a new wheat-Thinopyrum substitution line with stripe rust resistance. Euphytica 2011, 177, 169-177. 
29. Lammer, D.; Cai, X.; Arterburn, M.; Chatelain, J.; Murray, T.; Jones, S. A single chromosome addition from Thinopyrum elongatum confers a polycarpic, perennial habit to annual wheat. J. Exp. Bot. 2004, 55, 1715-1720.

30. Hu, L.J.; Liu, C.; Zeng, Z.X.; Li, G.R.; Song, X.J.; Yang, Z.J. Genomic rearrangement between wheat and Thinopyrum elongatum revealed by mapped functional molecular markers. Genes Genom. 2012, 34, 67-75.

31. Li, G.; Lang, T.; Dai, G.; Li, D.; Li, C.; Song, X.; Yang, Z. Precise identification of two wheat-Thinopyrum intermedium substitutions reveals the compensation and rearrangement between wheat and Thinopyrum chromosomes. Mol. Breed. 2015, 35, doi:10.1007/s11032-015-0202-z.

32. Li, J.; Endo, T.R.; Saito, M.; Ishikawa, G.; Nakamura, T.; Nasuda, S. Homoeologous relationship of rye chromosome arms as detected with wheat PLUG markers. Chromosoma 2013, 122, 555-564.

33. Zhang, P.; Li, W.; Friebe, B.; Gill, B.S. Simultaneous painting of three genomes in hexaploid wheat by BAC-FISH. Genome 2004, 47, 979-987.

34. Mukai, Y. In situ hybridization. In: Plant Chromosomes: Laboratory Method; Fukui, K., Nakayama, S., Eds.; CRC Press: Boca Raton, FL, USA, 1996; pp. 155-170.

35. Schwarzacher, T. DNA, chromosomes, and in situ hybridization. Genome 2003, 46, 953-962.

36. Cuadrado, A.; Jouve, N. Chromosomal detection of simple sequence repeats (SSRs) using nondenaturing FISH (ND-FISH). Chromosoma 2010, 119, 495-503.

37. Cuadrado, A.; Golczyk, H.; Jouve, N. A novel, simple and rapid nondenaturing FISH (ND-FISH) technique for the detection of plant telomeres. Potential used and possible target structures detected. Chromosome Res. 2009, 17, 755-762.

38. Danilova, T.V.; Friebe, B.; Gill, B.S. Single-copy gene fluorescence in situ hybridization and genome analysis: Acc-2 loci mark evolutionary chromosomal rearrangements in wheat. Chromosoma 2012, 121, 597-611.

39. Schmidt, T.; Heslop-Harrison, J.S. High-resolution mapping of repetitive DNA by in situ hybridization: Molecular and chromosomal features of prominent dispersed and discretely localized DNA families from the wild beet species Beta procumbens. Plant Mol. Biol. 1996, 30, 1099-1113.

40. Cuadrado, Á.; Schwarzacher, T. The chromosomal organization of simple sequence repeats in wheat and rye genomes. Chromosoma 1998, 107, 587-594.

41. Fu, S.; Chen, L.; Wang, Y.; Li, M.; Yang, Z.; Qiu, L.; Yan, B.; Ren, Z.; Tang, Z. Oligonucleotide probes for ND-FISH analysis to identify rye and wheat chromosomes. Sci. Rep. 2015, 5, doi:10.1038/srep10552.

42. Han, Y.; Zhang, T.; Thammapichai, P.; Weng, Y.; Jiang, J. Chromosome-Specific Painting in Cucumis Species Using Bulked Oligonucleotides. Genetics 2015, 200, 771-779.

43. Li, G.R.; Liu, C.; Zeng, Z.X.; Jia, J.Q.; Zhang, T.; Zhou, J.P.; Ren, Z.L.; Yang, Z.J. Identification of $\alpha$-gliadin genes in Dasypyrum in relation to evolution and breeding. Euphytica 2009, 165, 155-163.

44. Liu, C.; Qi, L.; Liu, W.; Zhao, W.; Wilson, J.; Friebe, B.; Gill, B.S. Development of a set of compensating Triticum aestivum-Dasypyrum villosum Robertsonian translocation lines. Genome 2011, 4, 836-844.

45. Zhang, R.; Wang, X.; Chen, P. Molecular and cytogenetic characterization of a small alien-segment translocation line carrying the softness genes of Haynaldia villosa. Genome 2012, 55, 639-646. 
46. Hayes, R.C.; Newell, M.T.; DeHaan, L.R.; Murphy, K.M.; Crane, S.; Norton, M.R.; Wade, L.J.; Newberry, M.; Fahim, M.; Jones, S.S.; et al. Perennial cereal crops: An initial evaluation of wheat derivatives. Field Crops Res. 2012, 133, 68-89.

47. Gazza, L.; Galassi, E.; Ciccoritti, R.; Cacciatori, P.; Pogna, N.E. Qualitative traits of perennial wheat lines derived from different Thinopyrum species. Genet. Resour. Crop Evol. 2015, doi:10.1007/s10722-015-0240-8.

(C) 2015 by the authors; licensee MDPI, Basel, Switzerland. This article is an open access article distributed under the terms and conditions of the Creative Commons Attribution license (http://creativecommons.org/licenses/by/4.0/). 